\title{
Clinical Prevention of peri-implantitis (Risk Indicators, Diagnosis, and Treatment)
}

\author{
Sang Ha KIM, Chung Jae LEE, Kyung Sook HWANG* \\ Dept. of Dent. Tech., Shin Han Univ., Korea
}

\begin{abstract}
Introduction: Peri-implant diseases are defined as inflammatory lesions of the surrounding peri-implant tissues and include peri-implant mucositis (an inflammatory lesion limited to the surrounding mucosa of an implant) and peri-implantitis (an inflammatory lesion of the mucosa that affects the supporting bone with resulting loss of osseointegration). Despite the success rates of dental implants, peri-implantitis presents as the most common complication in implant dentistry. This review discusses various factors associated with peri-implantitis and various available treatments, highlighting their advantages and disadvantages. Relevant articles on peri-implantitis published in English were reviewed from August 2010 to April 2020 in MEDLINE/PubMed, Scopus, and ScienceDirect.

The main discourse: The identified risk indicators of peri-implant diseases are plaque, smoking, history of periodontitis, surface roughness, residual cement, emergence angle $>30$ degrees, radiation therapy, keratinized tissue width, and function time of the implant, sex, and diabetes. Peri-implantitis treatments can be divided into nonsurgical (mechanical, antiseptic, and antibiotics), surface decontamination (chemical and laser), and surgical (air powder abrasive, resective, and regenerative). However, mechanical debridement alone may fail to eliminate the causative bacteria, and this treatment should be combined with other treatments (antiseptics and surgical treatment). Surface decontamination using chemical agents may be used as an adjuvant treatment; however, the definitive clinical benefit is yet not proven. Laser treatment may result in a short-term decrease in periodontal pocket depth, while air powder abrasive is effective in cleaning a previously contaminated implant surface. Surgical elimination of a pocket, bone recontouring and plaque control are also effective for treating peri-implantitis. The current evidence indicates that regenerative approaches to treat peri-implant defects are unpredictable.
\end{abstract}

Keywords: Clinical Prevention, peri-implantitis, MEDLINE, PubMed

Acknowledgement: This study is supported by Uniance's Central Research Institute.

Copyright (C) 2021. Korean Academy of Preventive Dentistry. All rights reserved.

This is an Open Access article distributed under the terms of the Creative Commons Attribution Non-Commercial License (http://creativecommons.org/licenses/ by-nc/4.0) which permits unrestricted non-commercial use, distribution, and reproduction in any medium, provided the original work is properly cited. 